\title{
Erratum to: Leveraging feature generalization and decomposition to compute a well-connected midsurface
}

\author{
Yogesh H. Kulkarni ${ }^{1}$ (I) $\cdot$ Anil Sahasrabudhe ${ }^{1} \cdot$ Mukund Kale $^{2}$
}

Published online: 2 August 2016

(C) Springer-Verlag London 2016

\section{Erratum to: Engineering with Computers (2016) \\ DOI 10.1007/s00366-016-0466-x}

Unfortunately two authors were missed in the author lists of the original publication.

The correct version of the author lists and affiliations is given below:

Yogesh H. Kulkarni, Anil Sahasrabudhe and Mukund Kale

Yogesh H. Kulkarni, Ph.D. Student, College of Engineering Pune, India, kulkarniyh12.mech@coep.ac.in

Anil Sahasrabudhe, Director, College of Engineering Pune, India, director@ coep.ac.in

Mukund Kale, Manager, Siemens PLM, Pune, India, Mukund_kale@hotmail.com

The above mentioned changes have been corrected in the original publication.

The online version of the original article can be found under doi:10.1007/s00366-016-0466-x.

Yogesh H. Kulkarni

kulkarniyh12.mech@coep.ac.in

Anil Sahasrabudhe

director@coep.ac.in

Mukund Kale

Mukund_kale@hotmail.com

1 College of Engineering Pune, Pune, India

2 Siemens PLM, Pune, India 